\title{
Engineered ecosystem development for Agro-Process Intensification
}

\author{
G. Akay ${ }^{1,2,3} \&$ S. Fleming ${ }^{1}$ \\ ${ }^{1}$ Process Intensification and Miniaturization (PIM) Centre, \\ School of Chemical Engineering and Advanced Materials, \\ Newcastle University, Newcastle upon Tyne, UK \\ ${ }^{2}$ The Institute of StemCell Biology and Regenerative Medicine, \\ Newcastle University, Newcastle upon Tyne, UK \\ ${ }^{3}$ Institute for Nanoscale Science and Technology, Newcastle University, \\ Newcastle upon Tyne, UK
}

\begin{abstract}
The principles of Process Intensification and Miniaturization technology, originally developed for chemicals processing, biotechnology and tissue engineering were applied to achieve plant growth and crop yield enhancement, which can be described as AgroProcess Intensification (A-PI). The basic principle of A-PI is the enhancement of multiple interactions between plant roots, water, nutrients, bacteria using micro-(bio)reactors as synthetic rhizosphere in soil (SRS) which is a highly porous nano-structured hydrophilic ionic macro-porous polymer. If soil fertility is not limited by water, nutrients or bacteria then these soil additives do not have any function, although they can still be used as root delivery system for plant protection. In this study, we used nutrient and bacterium depleted soil with or without water stress to grow soybean in order to demonstrate the effect of the SRS in enhancing biomass growth under stress. Through an extensive scanning electron microscopy studies, it is shown that AgroProcess Intensification is achieved through the association of the plant roots with SRS which retains both soil water and nutrients and transfer them to the plant while protecting the nitrogen fixing bacterium. Implications of this method are discussed in terms of engineering of ecosystem to grow crops and biomass in substandard soil under water and fertilizer stress.
\end{abstract}

Keywords: AgroProcess Intensification, agriculture, fertilizer stress, nitrogen fixation, soil additives, symbiosis, synthetic rhizosphere, water stress. 


\section{Introduction}

The objective of this study is to investigate the use of highly hydrophilic, ionic, elastic nano-structured macro-porous polymers prepared by high internal phase emulsion polymerisation and subsequently modified/functionalised and utilised as soil additives in order to enhance the growth of plants under fertilizer and water stress. The basic polymers are generically known as PolyHIPE Polymers (PHPs) which are modified and used as Synthetic rhizosphere (SRS) media. If used on a large scale in nutrient deficient soil under water stress, these materials can achieve:

1. Water regulation/conservation; 2. Fertilizer slow release/conservation; 3. Delivery of plant growth regulators; 4. Biological control of pathogens; 5. Reforestation; 6. Root infection for nitrogen fixation; and 7. Mixed bacterial inoculants for enhanced crop yield/nitrogen fixation.

The biodegradability of these materials can be controlled. If left within the soil for several years, they will become part of the ecosystem. Although their concentration in soil is low, due to their very low density and very high water adsorption capacity, they substantially enhance the soil quality while supporting the beneficial bacteria which are included initially in them. The use of bioactive SRS-media as soil additives is particularly important in nitrogen fixing plants.

\subsection{Processing in ecosystem}

Nature's processing in photosynthesis through plants involves two domains; plant leaves and plant roots. Although the synthesis involving leaves and roots can also be deemed highly efficient, the accessibility to conversion energy (solar energy) by the leaves and to nutrients, water and catalysts (soil microorganisms and plant exudates) are on the other hand highly inefficient since the mass transfer area density TAD (surface area per unit volume) in both cases is very small and in the case of plant root system, to some extent, it is also random. This randomness emanates from the fact that soil is the carrier medium for water, nutrients and microorganisms. Although there are inherent mechanisms to promote root interactions with nutrients/water/microorganisms, these mechanisms are not efficient due antagonistic interactions between water and nutrients / microorganisms; as uncontrolled water supply results in the depletion of nutrients and microorganisms from the rhizosphere where the many-body interactions take place. Nevertheless, water is also essential for nutrient and bacterium delivery to plant roots. But this process is far from efficient. One of the outcomes of the antagonistic effects is the washing of fertilizers from the soil; it is estimated that $50-70 \%$ of the fertilizers are not utilised by the plant [1]. Furthermore, due to the presence of other microorganisms, even when single useful bacterium cultures are reintroduced into soil at very high population levels, it is immediately subjected to competitive and antagonistic effects from the indigenous microflora which results in population decline [2]. Finally, water holding capacity of soil is not large and water is distributed over a wide volume in soil. 


\subsection{Need for engineered ecosystem}

Technology led increases in crop yield achieved during 1970s and 1980s has not been replicated since then and the rate of enhancement has been falling [3]. Increasing demand for food as well as energy crops poses huge challenges for the sustainability of terrestrial ecosystems. Current trends in agriculture add to these concerns. They include, diminishing returns of fertilizer application, water stress and rapid approach to climate-adjusted genetic yield potential ceiling which indicates that there is a lack of large exploitable 'yield gap' in agriculture [4].

In order to combat these challenges, several strategies are currently under development [5]. We have recently shown [6-8] how plant growth and crop yield enhancement can be achieved through simultaneous water regulation, fertilizer release and symbiosis; thus addressing most of the concerns cited above. Here, targeting of water, biological nitrogen fixation and delivery of fertilizer (including nitrogen) is achieved by associating plant roots with a synthetic symbiotic media. This technique differs fundamentally from other biomass/crop enhancement techniques using soil conditioners or slow release fertilizers or inter-cropping or biological nitrogen fixation because, in the present technique, the symbiotic-media is associated with the plant roots. Hence the delivery of the nutrients, water and bacterial activity, including root infection (leading to nodule formation for biological nitrogen fixation by bacteria in legumes) are regulated by the synthetic rhizosphere which is populated by root hairs.

\subsection{A model for AgroProcess Intensification}

In order to achieve selective root/water/nutrient/microorganism many-body interactions without any antagonistic effects while protecting useful soil bacteria, conserving water and nutrients, we use a symbiotic-media as soil additives. These materials act as micro-bioreactors for the efficient delivery of water and nutrients to the plant roots and preserve the activity of bacteria by creating a synthetic rhizosphere, essentially modifying the ecosystem. However, in order to ensure that the plant roots selectively seek and associate with SRS, several restrictions are placed on the type of material used as SRS; they include high water adsorption rate and capacity, elasticity, pore size, nano-porosity of the pore walls, ability to act as an efficient support for bacteria so as to utilise the 'confinement phenomenon' to achieve BioProcess Intensification [9, 10]. AgroProcess Intensification through the application of process intensification and miniaturization principles is only possible if the root growth selectively targets the symbiotic media and root hairs and primary roots extensively form a network through it. The observed extensive root association clearly indicates that the roots are directed towards the source of water and nutrients. It is this property of the plant roots that allows the extensive root and symbiotic-media association and makes the process selective rather than random.

The many body interactions within SRS results in process intensification through the same mechanism as that observed in process intensification and 
miniaturization [11] in which the mass transfer is enhanced by the reduction in diffusion path, accessibility of catalytic sites and enhancement of TAD. In addition, 'side reactions' are inhibited, catalyst concentration/activity is maintained through the protection of useful bacteria and high concentration of root exudates is present in SRS. Roots growing out of the SRS are already infected with bacteria and needs no further nodulation.

\section{Experimental}

\subsection{Preparation of synthetic rhizosphere media polymers}

All chemicals needed for the preperation of PolyHIPE Polymers (PHP) were purchased from Sigma-Aldrich. They include styrene, divinyl benzene, sorbitan monooleate (Span 80), potassium persulphate and concentrated sulphuric acid $(98 \%)$. The polymer was prepared using the following method [12] which is conducted in three stages; emulsification, polymerisation and functionalization (in this case, sulphonation was used to render the polymer hydrophilic and elastic). The aqueous phase composition in the emulsification stage consisted of $5 \mathrm{wt} \%$ concentrated sulphuric acid, $94 \mathrm{wt} \%$ deionised water and $1 \mathrm{wt} \%$ potassium persulphate. The oil phase was made up of $76 \mathrm{wt} \%$ styrene, $14 \mathrm{wt} \%$ sorbitan monooleate (Span 80; surfactant) and $10 \mathrm{wt} \%$ divinyl benzene (DVB, used as cross-linking agent). The two phases were mixed in a $12 \mathrm{~cm}$ diameter mixing vessel equipped with a stirrer with two flat paddles set at right angles close to the bottom of the vessel. The total polymer volume of one batch was $250 \mathrm{ml}$ of which $90 \%(225 \mathrm{ml})$ was aqueous phase and $10 \%(25 \mathrm{ml})$ is oil phase. The oil phase was added to the mixer which was set at $300 \mathrm{rpm}$. The aqueous phase was added with a peristaltic pump at the rate of $45 \mathrm{ml} /$ minute (i.e. dosing time of 5 minutes), followed by a mixing time of 1 minute. The emulsion was then drained from the mixer into $5 \times 50 \mathrm{ml}$ plastic tubes, capped, inverted and placed in an oven at $60^{\circ} \mathrm{C}$ for 8 hours for polymerisation to take place. The polymer was then cut into $4 \mathrm{~mm}$ discs then dried overnight in an oven at $60^{\circ} \mathrm{C}$.

Sulphonation of PHP was achieved by soaking the discs in $98 \%$ sulphuric acid for 2 hours, then microwaving in a conventional $1 \mathrm{~kW}$ kitchen microwave oven for 30 seconds followed by turning over the samples and repeating the irradiation for another 30 seconds. Total irradiation time was 150 seconds [13]. The sulphonated discs were washed with deionised water for 30 minutes twice, followed by 60 minutes soaking in $2.5 \mathrm{~N}$ ammonium hydroxide. Excess ammonium hydroxide was then removed by neutralising with acetic acid and washing with distilled water, bringing the $\mathrm{pH}$ down to $6.2 \pm 0.8$. These polymers measured ca. $5 \times 5 \times 5 \mathrm{~mm}^{3}$.

\subsection{Scanning Electron Microscopy (SEM)}

Dry samples of polymer were prepared for examination with SEM by gold coating using a Polaron E1500 Sputter Coater. Polymers with roots growing through are first treated to fix the roots using $2 \%$ glutaraldehyde/phosphate 
buffer solution, then dehydrated in progressively more concentrated ethanol $10 \%, 25 \%, 50 \%, 75 \%, 100 \%, 10$ minutes per concentration. Samples were then critical-point dried with liquid $\mathrm{CO}_{2}$, followed by gold coating the same as the dry polymer samples $[12,13]$. Samples were then examined using a Cambridge S240 scanning electron microscope.

\subsection{Soil preparation}

The growth medium used was made up of $75 \%$ Wilkinsons (UK supplier) soil and $25 \%$ horticultural sand. The soil mixture was washed to remove some of the nutrients producing a product with lower fertility so that any effect the polymer was having on plant growth would be evident earlier. The soil was washed by adding 10 litre of water to $2.5 \mathrm{~kg}$ of dry soil. The washing was monitored by measuring the conductivity of the water over the washing period. The conductivity of tap water was $315 \mu \mathrm{S} / \mathrm{cm}$. After 24 hours, with occasional stirring, the conductivity increased to $775 \mu \mathrm{S} / \mathrm{cm}$ (average of 3 samples). The water was drained and further 10 litres of water added. After a further 24 hours, the conductivity averaged $506 \mu \mathrm{S} / \mathrm{cm}$. The conductivity due to soil electrolytes was therefore reduced from $460 \mu \mathrm{S} / \mathrm{cm}$ to $191 \mu \mathrm{S} / \mathrm{cm}$.

Soil was then dried in trays and sterilised in an autoclave in $500 \mathrm{~g}$ aliquots in autoclavable plastic bags. The nitrogen, phosphorus and potassium content of the soil were measured, in triplicate, before and after washing.

\subsection{Planting of soybeans}

Soybeans (Glycine max, variety Pan) from South Africa were used in these experiments. Plants were grown in the soil/sand mixture in a greenhouse in $13 \mathrm{~cm}$ diameter pots. PolyHIPE Polymer was added to the soil at $0.5 \%$ by weight [6-8]. These pots hold 500g of soil; therefore $2.5 \mathrm{~g}$ of PHP was added to each pot. Polymer was only added to the soil below the level of the seed.

Four treatments were used in this experiment: (1) Soybeans under normal watering; (2) Soybeans under reduced watering; (3) Soybeans with PHP under normal watering and (4) Soybeans with PHP under reduced watering. Normal watered plants were watered twice a week with $100 \mathrm{ml}$ water. Reduced watered plants were watered twice a week with $50 \mathrm{ml}$ water. Each treatment was replicated 6 times. Plants were harvested after 15 weeks and the length, fresh weight and dry weight of the shoots and the fresh weight and dry weight of the roots were recorded.

\section{Results and discussion}

\subsection{Soil characteristics}

The results of the soil analysis before and after washing are shown in Table 1. After washing, nitrogen content was reduced by $36.4 \%$, phosphorus by $32.2 \%$ and potassium by $46.5 \%$. There was no bacterium in the soil due to sterilization. 
Table 1: $\quad$ Soil nutrient content before and after washing.

\begin{tabular}{|l|c|c|}
\hline Nutrient type & Before washing & After washing \\
\hline Nitrogen & $0.22 \mathrm{wt}^{\circ} \%$ & $0.14 \mathrm{wt} \%$ \\
\hline Phosphorus & $8.66 \mu \mathrm{g} / \mathrm{ml}$ & $5.87 \mu \mathrm{g} / \mathrm{ml}$ \\
\hline Potassium & $203 \mu \mathrm{g} / \mathrm{ml}$ & $108.5 \mu \mathrm{g} / \mathrm{ml}$ \\
\hline
\end{tabular}

\subsection{Biomass growth}

Growth of biomass in terms of soybean height, shoot and root weight (fresh or dry) under normal and reduced (droughted) watering are shown in Figures 1-3. As seen in these figures, the addition of SRS-polymer significantly increases the shoot length and weight of both shoots and roots compared to the control plants.

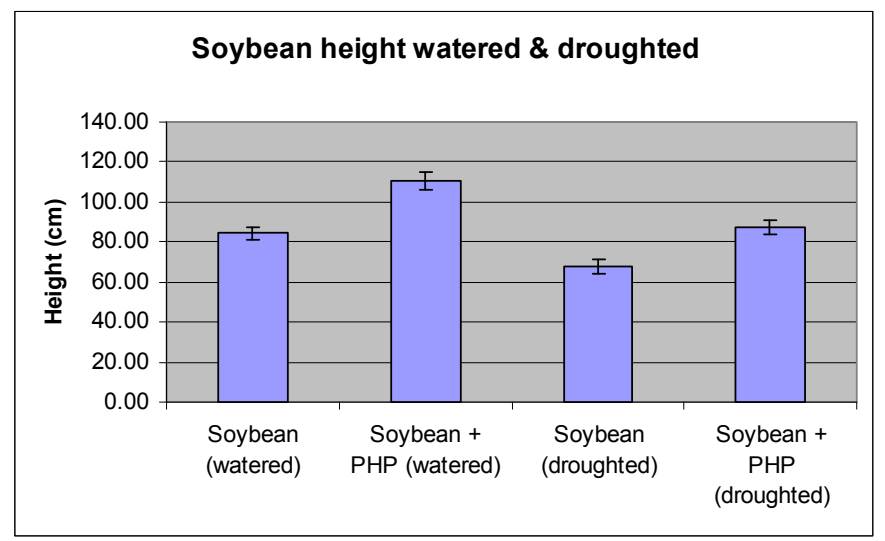

Figure 1: Average soybean height under normal and reduced (droughted) watering conditions.

Figure 1 shows that the addition of PHP has had a significant effect on the shoot length both of normally watered plants and droughted plants. Watered plants with SRS-polymer were 30.8\% longer than control plants. Although droughted plants were $20.2 \%$ shorter than the normally watered control plants, the addition of SRS-polymer increased the length of droughted plants by $29.7 \%$ compared to the droughted plants with no SRS-polymer.

Figure 2 shows that compared to the control group (no SRS-polymer) the following enhancements in biomass growth were obtained when SRS-polymer was used: Normally watered shoot fresh weight increased by $84.2 \%$. Droughted shoot fresh weight increased by $71.8 \%$. Normally watered root fresh weight increased by $87.5 \%$ compared to control. Droughted root weight with SRSpolymer increased by $26.9 \%$. 


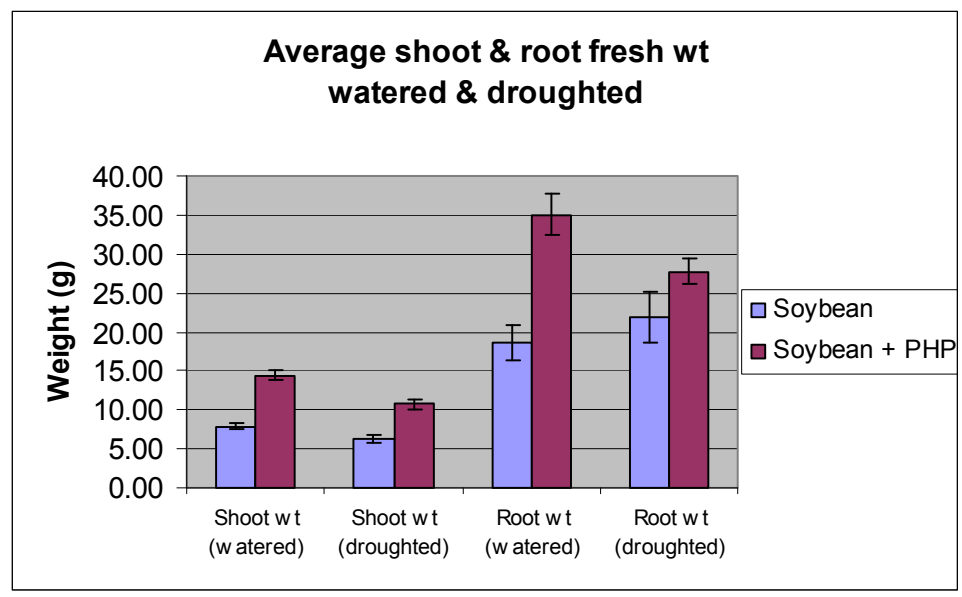

Figure 2: Average soybean shoot and root fresh weight under normal and reduced (droughted) watering conditions.

Figure 3 shows that compared to the control group (no SRS-polymer), the following enhancements in biomass growth were obtained when SRS-polymer was used: Normally watered shoot dry weight increased by $111.9 \%$. Droughted shoot dry weight increased by $106.4 \%$. Watered root dry weight increased by $50.8 \%$. Droughted root dry weight increased by $4.4 \%$ compared to control.

The trends in the enhancements in biomass yield both in fresh and more significantly in dry weight are similar and consistent with our earlier results [68]. It is interesting to note that under drought conditions, although dry shoot weight increases by $106.4 \%$, the increase in dry root weight is only $4.4 \%$, indicating that the available roots are more efficient in the presence of SRSpolymer in sustaining the growth of biomass compared with the control (no SRSpolymer).

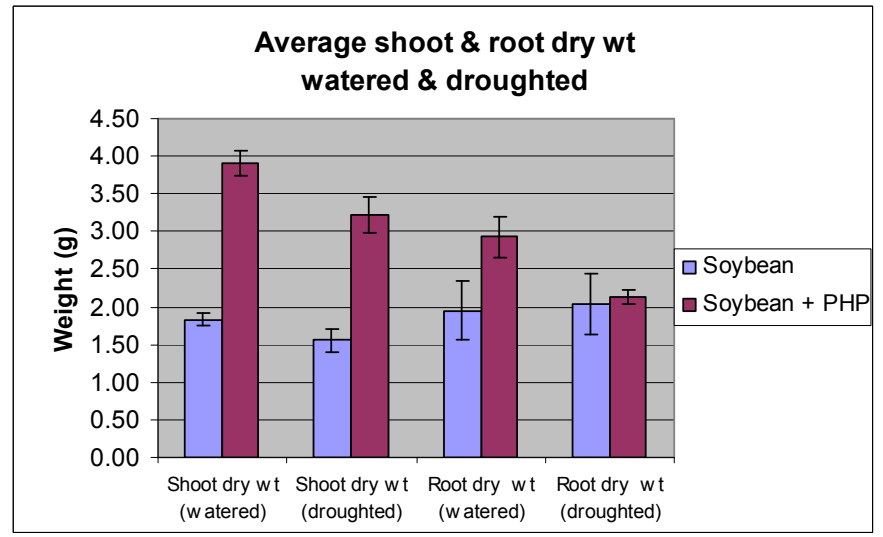

Figure 3: Average soybean shoot and root dry weight under normal and reduced (droughted) watering conditions. 


\subsection{Root association with SRS-polymer}

When rigid sulphonated PHP is used as soil additives, the observed enhancement in biomass yield is not as significant as with elastic PHP which also has large pore and interconnect hole size. Root association with SRS-polymers is especially important when biologically active SRS-polymers are used for root infection by nitrogen fixing bacteria [6-8].

Figure 4 shows the soybean root association with SRS-polymer. The internal structure of the SRS-polymer is shown in Figures 5 and 6. Figure 5 illustrates the sulphonated PHP micro-structure used in the experiments while Figure 6 illustrates the root association.

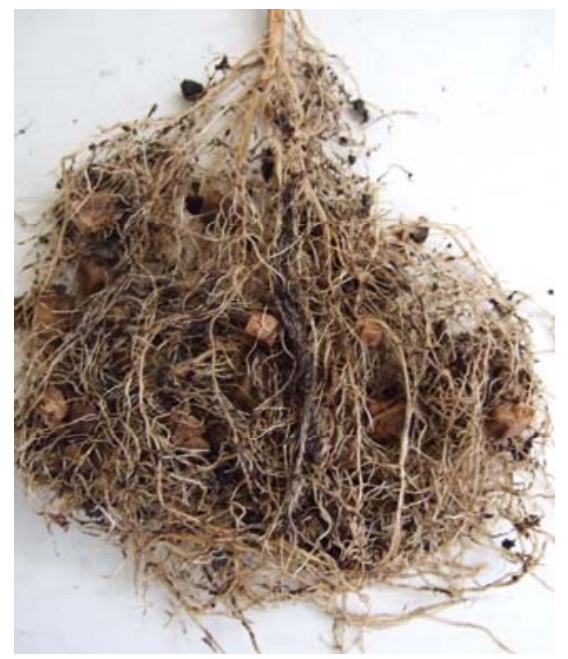

Figure 4: $\quad$ Roots of soybean and SRS-polymer after a growth of 15 weeks.

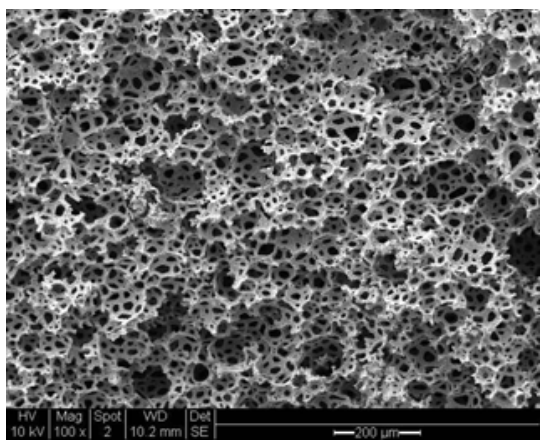

(a)

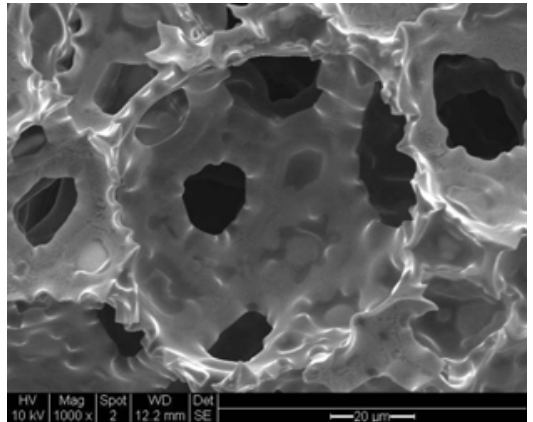

(b)

Figure 5: Micro-structure of sulphonated PolyHIPE Polymer before it is used as SRS-media. (a) Magnification 100x (Scale bar $200 \mu \mathrm{m}$ ); (b) Magnification 1000x (Scale bar: $20 \mu \mathrm{m})$. 


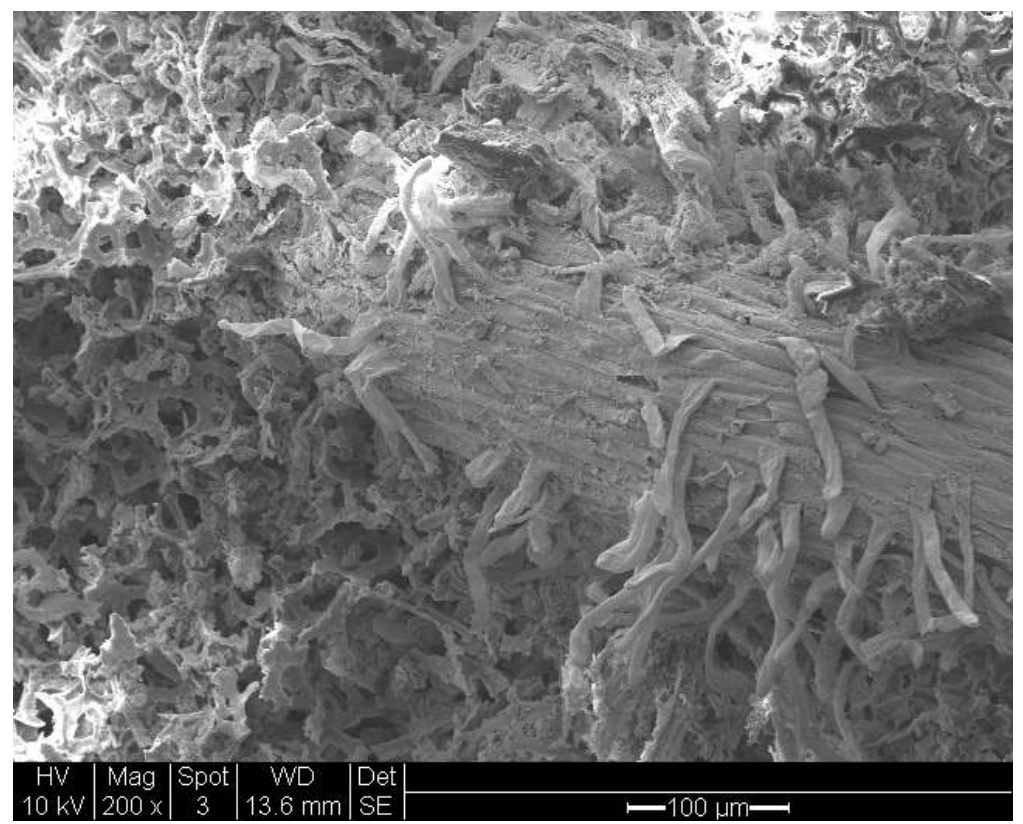

Figure 6: Fracture surface of SRS-media polymer showing soybean root growing through it with root hairs penetrating into the SRS-media.

It is clear from Figures 5 and 6 that although the pore and interconnect size of the SRS-media polymer is small compared with the size of soybean root, root penetration takes place and root hairs penetrate into the media. Under these conditions water and fertilizer transport to the root system is enhanced since diffusion path associated with this transport is now microns, rather than centimetres. As neither SRS-media polymers or soil contain any bacteria, the plant growth is solely dependent on the soil nitrogen and we have not observed any root exudates presence in the SRS-media. Root exudates are only present when SRS-media has supported bacteria.

\section{Conclusions}

Sulphonated elastic PolyHIPE Polymers were used as Synthetic Rhizosphere media in order to enhance biomass yield in soybean under fertiliser and water deficiency in the absence of any nitrogen fixation from air. Fertiliser levels falls during plant growth as a result of wash-out and plant metabolism. In our previous studies (for example grass growth), the effect of the SRS-media started showing after second or third harvest under normal watering. As nutrients were already depleted, the beneficial effects of the SRS-media became clear immediately even with normal watering. Under water stress, the observed effect is similar to those observed in our previous studies [6-8]. We have also shown 
that, under water stress, although there is substantial enhancement in biomass yield, increase in root weight in the presence of polymer is not significant in the presence of SRS-media, indicating that the available root mass is sufficient to sustain enhanced biomass growth.

\section{Acknowledgement}

We are grateful to the Engineering and Physical Sciences Research Council (EPSRC) for supporting this research and providing $\mathrm{PhD}$ studentship for Steve Fleming.

\section{References}

[1] Abraham, J., and Pillai, V. N. R., Membrane-encapsulated controlledrelease urea fertilizers based on acrylamide copolymers, J. Appl. Polymer Sci., 60, 2347-2351 (1996).

[2] Bashan, Y., Inoculants of plant growth-promoting bacteria for use in agriculture. Biotechnol. Adv., 16, 729-770 (1998).

[3] Conway, G. and Toenniessen. G., Feeding the world in the twenty-first century. Nature, C55-C58 (1999).

[4] Tilma, D., Cassman, K. G., Matson, P. A., Naylor, R. and Polasky, S., Agricultural sustainability and intensive production practices. Nature 418, 671-677 (2002).

[5] Ashraf, M., Ozturk, M., and Athar, H. R., Salinity and water stress: Improving crop efficiency Springer, Heidelberg (2009).

[6] Akay, G., Burke, R.D., Synthetic symbiosis system as soil additives to deliver active ingredients through plant roots for enhanced plant and crop yield. International Patent Publication Number WO/2010/040996 (2010).

[7] Burke, D. R., Akay, G. and Bilsborrow, P., Development of novel polymeric materials for AgroProcess Intensification. J. Appl. Polymer Sci. 118, 3292-3299 (2010).

[8] Akay, G. and Burke, R. D., Synthetic symbiosis system as soil additives to deliver active ingredients through plant roots for enhanced plant and crop yield. Plant and Soil (submitted for publication).

[9] Akay, G., Erhan, E., Keskinler, B., Bioprocess intensification in flow through micro-reactors with immobilized bacteria, Bioengineering Biotechnology, 90, 180-190 (2005).

[10] Akay, G., Microporous polymers. International Patent Publication Number WO 2004/005355, (2004).

[11] Akay, G., Process intensification and miniaturization. p. 183-199, In: S. Lee, ed. Encyclopedia of chemicals processing, Vol. 1. Taylor and Francis, New York, (2006).

[12] Akay, G., Bokhari, M. A., Byron, V. J. and Dogru, M., Development of nano-structured materials and their application in bioprocess-chemical process intensification and tissue engineering. In: Chemical Engineering 
Trends and Developments, Ed: M.A. Galan and E. M. Del Valle, Wiley, London. pp. 171-196 (2005).

[13] Akay, G., Noor, Z. Z., Calkan, O. F., Ndlovu, T. M., and Burke, D. B., Process for preparing a functionalised polyHIPE polymer, US Patent 07820729 (2010). 